\title{
The impact of widespread covid-19 on small business venture in Aceh province: a recuperation strategy from entrepreneurs' point of view
}

\author{
Syafruddin Chan $^{1 *}$, Kurnia Asni². \\ ${ }^{1}$ Management Department, Syiah Kuala University, USK Darussalam Campus, Banda Aceh, 23111, Indonesia \\ ${ }^{2}$ Master in Management Department, Abulyatama University, Unaya Lampoh Keude Campus, Aceh Besar, 23272, \\ Indonesia
}

\begin{abstract}
This study aims to analyse the real impact of the COVID-19 pandemic for small businesses and what recuperation strategy needs to be implemented from the perspective of business owners including opportunities for using digital business technology and what the business owner expects from government to help the recover. This research was conducted using a quantitative descriptive method. Data collected using online questionnaires, through various MSBE communities in Aceh. 150 questionnaires distributed using non-probability sampling. In addition, several interviews with respondents were conducted to gain insight into the impact of covid-19 on their business. The spread of Covid-19 did have a negative impact on the small businesses that were respondents in this study. The biggest impact is the decline in sales because the demand for its products and services is decreasing. As a result, employers did the downsizing of by decreasing their business scale, and laying off employees. Entrepreneurs also ask for debt restructuring in banking institutions to reduce pressure on the declining cash in the company. At the same time, companies are starting to use technology to enter digital businesses, including joining online applications and selling in e-markets more intensively.
\end{abstract}

\section{Introduction}

Micro, Small and Medium Enterprises (MSMEs) are one of the sectors most affected by the Covid-19 pandemic, including MSMEs in Aceh Indonesia. Economic growth in Aceh before covid-19 grew by an average of 2.90 percent per year. However, after the existence of covid-19, the growth shrank by 0.37 percent. One of the reason is because of government policies that limit people's movement as well as changes in people's own behavior which tends to limit activities outside their house (1). The sectors most affected by this outbreak are food and beverage, accommodation and retail businesses. The impact on MSMEs is the decline in sales, the difficulty of raw materials, hampered distribution, as well as finance and production process (2). This phenomenon is supported by Bank Indonesia research which states that as many as 87.5 percent of MSMEs are affected by the Covid- 19 pandemic Of this amount, around 93.2 percent of them were negatively affected on the sales side which ultimately put pressure on profits and cash flow (3). The COVID-19 crisis is causing major problems and its impact will be felt in the long term on the global economy (4). Although vaccination programs that have been carried out throughout the world have generated optimism, the economic outlook in the long term is always uncertain. In general, global economic growth declined by $3.4 \%$ in
2020 (5). Economic growth is expected to recover by $5.6 \%$ in 2021 , but recovery will depend largely on the spread of virus variants and the effective distribution of vaccines, which the government is undertaking to prevent its development (6).

With the COVID-19 pandemic, its impact is clearly felt in every region and every industry. On the other hand, when lockdowns or social distancing forced consumers to stay at home, the e-commerce industry experienced fairly rapid growth which was reflected in a surge in online sales volume, as well as online business ratings and reviews that increased from 40 to 80 percent higher during this pandemic. Old business strategies like brand equity, more advertising spend, and big promotions are simply less relevant in an age when consumers have access to so much word of mouth (7).

This pandemic additionally affects the development of small enterprises. Micro, Small and Medium Enterprises (MSMEs) are regularly more influenced than large companies undertakings by the COVID-19 emergency particularly for the most weak sectors, for example, discount and retail exchange, transportation, convenience store, food industries, proficient and other individual services. Also, small organizations think that it is harder to exploit various wellsprings of money, including from the market. Then again, small

\footnotetext{
* Correspondent author: syafruddin.chan@unsyiah.ac.id
} 
organizations frequently depend intensely on held income and bank obligation. Small organizations have more fragile production network capacities than their bigger partners. MSMEs for the most part have more modest inventories and provider networks making them more powerless against store network disturbances and cost expands. Essentially, they have less dealing ability to authorize alluring instalment conditions. As indicated by the review among European MSMEs directed among February and May 2020, 51\% of respondents announced that late instalments put focus on their liquidity during the COVID-19 emergency, contrasted with $39 \%$ in 2019. Also, there has been a striking increment in the level of MSMEs that needed to acknowledge longer instalment terms than they anticipated (6). Small organizations are falling behind in engrossing advanced instruments and innovations that can assist with building flexibility in the current pandemic emergency. Reviews show that the pandemic has expanded the utilization of advanced innovation by MSMEs, notwithstanding generous contrasts between nations. Simultaneously, the contrasts between MSMEs - and specifically smaller firms - and big companies keep on being critical, with MSMEs take-up of advanced innovation generally a small portion of that by bigger companies (7).

The weakness of these small companies converted into a sharp decrease in income since the beginning of the pandemic at a rate quicker than their capacity to reduce working expenses, compromising an expected liquidity emergency among MSMEs. Between January 1 and April 1, 2020, US MSMEs income diminished by $40 \%$ to half (11) with income in January 2021 still down $31 \%$ contrasted with the earlier year.

The effect of the COVID-19 emergency on the appearance of MSMEs is significant. Of the MSMEs studied, $80 \%$ announced steady or expanding revenue for the year before the pandemic started. Right now, $80 \%$ of MSMEs say their revenue is declining. They likewise announced a few different impacts for instance worries about credit defaults $(25 \%)$, worries about their capacity to hold the staffs $(24 \%)$ and questions in their capacity to keep up with their inventory chains (28\%), any expectations of decreasing the quantity of workers after the pandemic $(28 \%)$ and deferring speculation for business extension (36\%). Generally, miserable assumptions for the general economy and the negative pattern in SME profit paint a stressing picture. Under current conditions, very nearly one out of five MSMEs reviewed accept they will be bankrupt by August 2021. That figure ascends to 60 percent for April 2022. A decrease in SME revenue will excessively affect the practicality of MSMEs: almost three of every four say they will be bankrupt by January 2022 if their pay falls by 10 to 30 percent (6). The monetary effect of the COVID-19 pandemic has likewise been felt by the MSMEs in Indonesia. The effect brought about by this pandemic incorporates 5 viewpoints, specifically the decrease of sales is by $61 \%$, the decline in gross profit is by $61 \%$, the quantity of MSMEs encountering capital issues expanded to $71.4 \%$, decreased the quantity of workers by $22 \%$, and reducing the capacity to pay bank loan. Practically all MSMEs experience issues in doing their commitments to the banks.

\subsection{For what reason do MSMEs need assistance?}

Protecting small businesses from widespread permanent closures is important because of the many roles they play in the economy, as employers, engines of entrepreneurship, economic multipliers, and community centers (12). Preceding the COVID-19 pandemic, independent ventures represented portion of private sectors occupations two third of the net new positions made from 2000 to 2017. Little and medium-sized ventures (MSMEs) represented $50 \%$ of the total revenue produced by organizations and 44 percent of labor force. Extremely durable conclusion of private companies is thought to bring about longer joblessness than leaves and impermanent cutbacks. Indeed, even as the economy recuperates, current representatives should look for some kind of employment at various organizations, conceivably diminishing their pay. Investigations of past downturns showed that individuals who lost their positions acquired 17.5 percent less in their new positions (12).

\subsection{Government support}

The COVID-19 emergency seriously affects SME incomes, and government support is key for these organizations (13). Policymakers can expect take-up in different help projects to keep on expanding for the time being. Governments all throughout the globe are reacting rapidly and unequivocally to the extraordinary difficulties MSMEs face because of the COVID-19 pandemic, through different improvement and backing measures. These actions zeroed in on crisis liquidity support in different structures, yet were progressively being joined by underlying scaffolding and a more extensive recuperation bundle. Both focal and nearby and provincial governments participated in the arrangement exertion (6).

General government support measures can be mentioned for example Job retention schemes in the form of wage subsidies. This approach targets forestalling a sharp ascent in joblessness just as to lift customer interest (14). Then, at that point conceded instalments incorporate deferral of instalment of pay and corporate assessments, esteem added charge, government managed retirement and benefits instalments, a ban on obligation instalments and waivers on lease instalments, waivers or premium cost decreases focused on keep up with liquidity and diminish the weight of MSMEs working expenses.

Other monetary help incorporates giving advance ensures, improved on layaway loaning methods, and backing through awards and sponsorships, or through value or semi values, including convertible credits (15). What's more, the public authority has additionally upheld the parts of SME business association instruments that plan to assist MSMEs with adjusting the changing business climate, for instance support including for teleworking and E-deals, support for innovation advancement and improvement, support for abilities redesigning, support for new companies, and for discovering new elective business sectors. From the 
table above, it can be seen that the most interventions carried out by the government to keep MSME companies operating and prevent them from going bankrupt are wage subsidies, loan guarantees, and income tax relaxation.

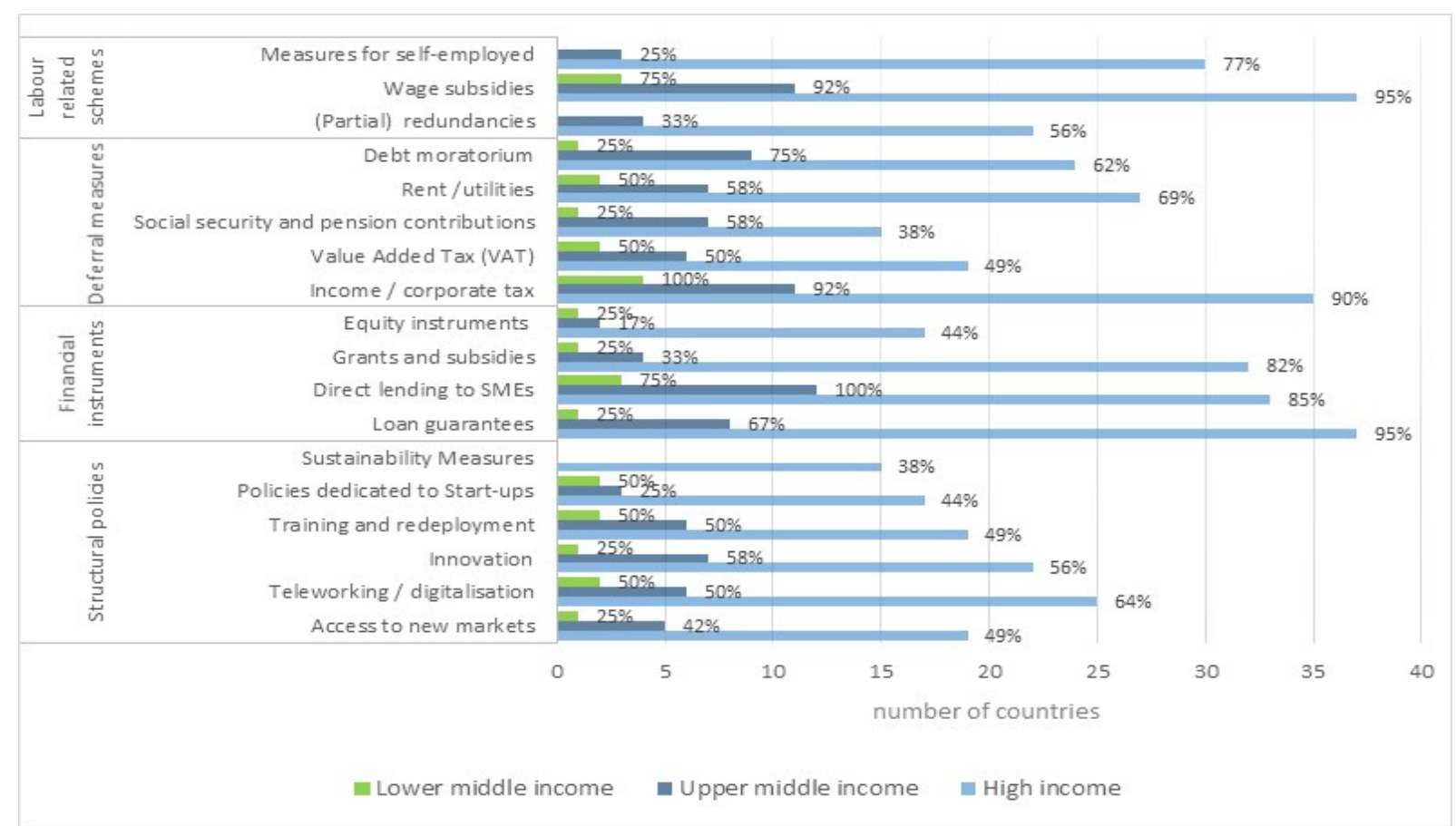

Fig. 1. Government support measures for MSMEs in response to the COVID-19 crisis.

Source: Annex A and OECD (2021), A one-year in-depth analysis of SME and entrepreneurship policy responses to COVID-19: lessons learned for the road to recovery.

\section{Opportunity during pandemic}

The condition of the COVID-19 corona pandemic, which was followed by the implementation of social distancing, gave rise to new consumer behavior, but on the one hand it opened up opportunities for banking, financial, and financial services businesses to spur marketing. The pandemic situation seems to have given rise to new consumer behavior, which is different in every Southeast Asian country. Now is a good time for banking, financial, and financial services businesses to do marketing. The players in the industry can take advantage of the digital space to promote loyal users, and even reach new users. At times like this, the majority of people tend to choose cashless transactions in order to maintain their health. The COVID-19 pandemic has indeed caused panic in financial markets. Many industries are feeling the impact of this situation, for example travel, hospitality, food and beverage, automotive, and entertainment $(2,16)$. In this situation, many companies and brands have temporarily suspended their marketing activities. Some even withhold these activities until the situation returns to normal and is under control. This results in a general decreasing in marketing activity. This is an opportunity for businesses to be able to take advantage of this situation to form new habits, and change their communication and sales channels to the digital space. This new habit is believed to persist even though the situation returns to normal. The shopping interest of the Indonesian people has not disappeared. Especially for online shopping, this interest actually grew rapidly during this crisis situation (17). With the closure of the majority of shopping centres, online shopping has become the main choice in meeting the needs, from daily to hobby. Seeing the interest in spending that does not subside, this opens up opportunities for banking, financial, and other financial services businesses. Moreover, several online buying and selling platforms encourage buyers and sellers to make cashless transactions by utilizing payment services such as credit cards, transfers, or e-wallet. So, he continued, this is the right time for banking, financial, and financial services businesses to boost marketing.

The urge to practice social distancing reduces community activities. In addition to decreasing the number of people visiting business activities such as shopping centres, the number of individuals traveling outside the city has also decreased drastically. The average decline in visits at several malls in Indonesia was reduced by more than 50 percent compared to the beginning of 2020 (18). COVID-19 is changing our lives. In this situation, we prefer to stay at home instead of traveling. Social distancing also makes us spend a lot of time in the digital space either for work, communicating, shopping, or just looking for entertainment. In Indonesia, the pandemic situation and social distancing gave rise to several new behaviors, for example, the adaptive shopper and working-from-home 
professionals. Regarding the adaptive shopper, since social distancing was announced, the use of shopping applications has increased by up to 300 percent. Applications that are widely used are shopping applications that sell various kinds of daily needs as well as special applications for buying and selling used goods. Meanwhile, for most workers in Indonesia, working-from-home is the same as working in a normal situation. They continue to do work, collaboration, communication, and meetings as usual. However, all the

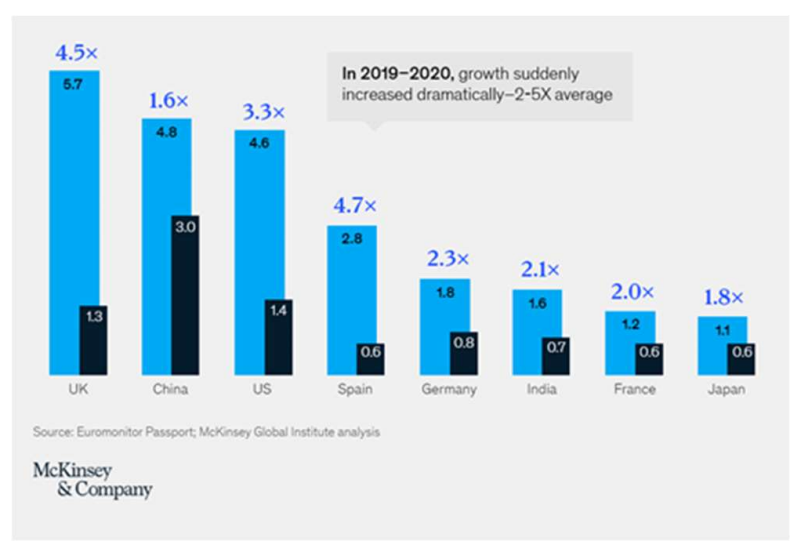

Fig. 2. Increase the business volume because of social distancing.

This phenomenon is certainly become a unique opportunity for small businesses affected by the pandemic to start taking advantage of this situation with changes in people's behavior, especially to enter the digital space and leave physical business activities as happened before the COVID-19 pandemic.

\section{Research method}

The following section discusses the recovery strategy carried out by small and medium enterprises in Aceh. The data presented in this section are primary data collected through questionnaires and direct interviews with business owners. This research was conducted using a quantitative descriptive method. Data collected using online questionnaires, through various MSME communities in Aceh. 150 questionnaires distributed using non-probability sampling. In addition, several interviews with respondents were conducted to gain insight into the impact of covid-19 on their business and of which 50 are small businesses which are assisted by the Syiah Kuala University Business Incubator, most of which are located in Banda Aceh and Aceh Besar.

\section{Recovery strategy}

The types of business are also quite diverse, although most of them are food producers. And then there is also personal care, diet food, herbs and dish cleaner. work is done at home with the help of productivity applications. The use of productivity applications rose by more than 400 percent in mid-March 2020 (18).

The opinion above is strengthened by the results of research conducted by (17) in various countries around the world and found an increase in the volume of ecommerce business up to 4.5 times compared to before the pandemic period as shown in the following figure.

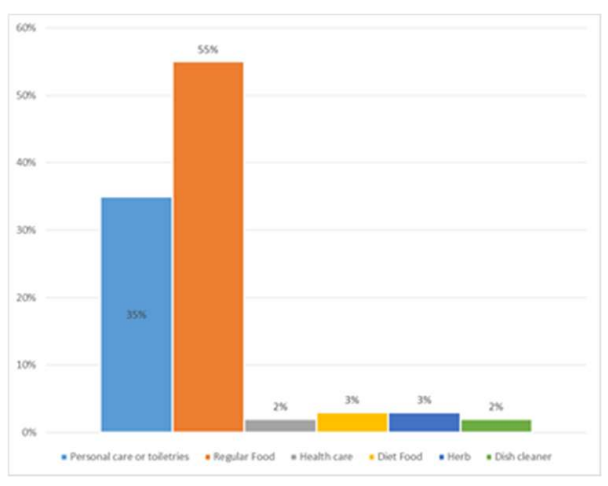

Fig. 3. Respondent's business profiles.

From the description of the respondent's business, it can be seen that the business of producing MSME products based on food is very dominant. Generally using raw materials that are in the area where the business stands. Such as tuna fish for Abon Ikan products produced by the Aroma brand, sambal Ijo which uses cayenne pepper as its main raw material or Cilet Chocolate which uses cocoa as raw material which is widely spread throughout Aceh. The second category is personal care, also generally produced by this MSME company using local raw materials such as Minyeuk Pret, a perfume product that uses local patchouli oil as a fragrance binder, then there is also Gayuen, which is a deodorant product that uses the main raw materials of whiting and lime and Yagi Natural is a cosmetic product that uses cocoa fat as its main raw material.

Of the several examples of MSMEs mentioned above, the majority do use local raw materials as their main raw materials. The use of specific local resources can lead to a comparative advantage. Comparative advantage can be turned into a competitive advantage if in utilizing local raw materials the company can save on raw material costs, which do not have to be imported from other regions. According to (19). When a company can do something or have something that competitors want, then the company represents a competitive advantage. According to the theory of competitive advantage, it is known that a company to be superior to other companies must have certain strategies and pay attention to the company's performance in order to improve every day, every month, and every year, if this is achieved then the company has a competitive advantage. In the context of companies in Aceh, they are actually in a better off position to win the competition.

In relation to the COVID-19 pandemic, the regional and central governments have actually made various efforts to help MSME companies to continue to exist during this pandemic crisis (20). However, not all of 
these MSME companies enjoy the convenience facilities provided by the government, either because the numbers are limited or the types are not in accordance with the needs of the MSMEs themselves, which are very specific and differ from one company to another. When asked what help do they hope for the most if there will be more assistance in the future related to this pandemic? So the answer is very diverse from one MSME to another. The largest number or $25 \%$ of the total respondents stated that working capital assistance was very much needed. Meanwhile, $20 \%$ of other MSMEs stated that what they need most at the moment is wage subsidies for their employees. For those who still have loans at the bank, they expect a moratorium and scheduling of instalment payments as well as relaxation of bank interest that must be borne (15\%). The same number $(15 \%)$ of them expect support for conversion to digital businesses and improvements to their digital business models (15\%), so that not only can they get out of crisis situations, but also take advantage of opportunities that arise as a result of the implementation of social distancing during this pandemic.

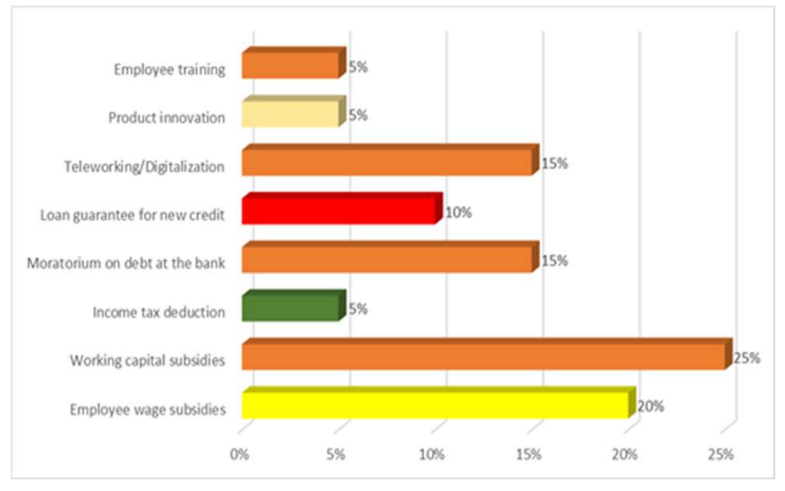

Fig. 4. Assistance expected from the government.

Some MSMEs also find it difficult to get bank loans, because they do not have enough guarantees to back up these bank loans (21). Therefore, $10 \%$ of the respondents hope that there will be guarantee assistance from the government so that they can increase their debt to the bank in the form of credit loans. While the remaining 5\% each expect new product development assistance, employee training and corporate income tax reductions.

The Indonesian government through the financial services authority (OJK) has taken various actions to assist MSMEs, including the interest subsidy program for micro, small and medium enterprises (MSMEs), a fund placement program to ensure banking liquidity which will be channelled to the banking sector, real estate loans, working capital credit guarantee programs for MSMEs, and programs for providing working capital to corporations, especially in the labourintensive sector (Fathiyah Wardah, 2020)

Regarding what has been done by MSMEs entrepreneurs in the Aceh region to keep their companies operating during this pandemic period, most of them have reduced production volume due to declining market demand (25\%). Efforts made by other MSME entrepreneurs are increasing their product marketing channels by utilizing online business or digital marketing as much as $18 \%$. Many were also forced to reduce employees (18\%) due to the decreasing number of activities in the company in the hope that they would be rehired when the situation improved. In addition, there are those who diversify their businesses by building fully digital businesses to respond to the increasing demand in online businesses as a result of social distancing (14\%).

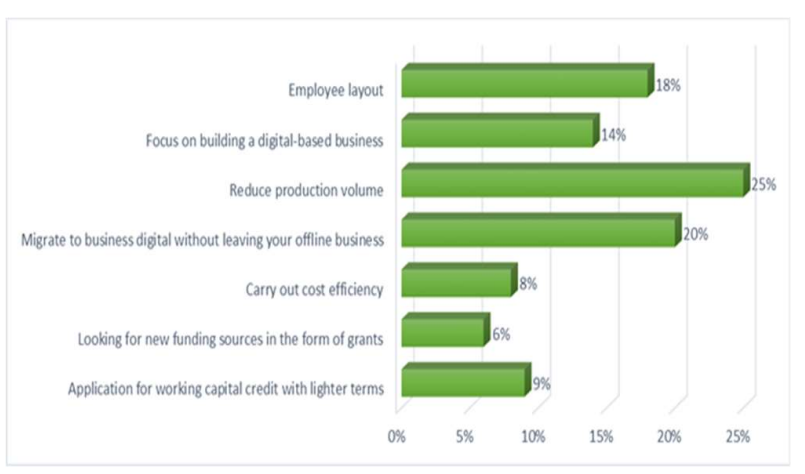

Fig. 5. What have been done to recover the business.

When asked to companies that use digital platforms as their recovery strategy, what do they do by migrating to digital businesses, then the answer is opening an online store in one or more e-market places in Indonesia such as Lazada, Shoppe, Bukalapak and Tokopedia $(80 \%)$. Some of them said they did promotions through social media such as Instagram shops, Facebook shops and took advantage of the Google shopping facilities. A small number of MKMs such as Yagi and Minyeuk Pret built their own websites, of course combining them with various social media application platforms to drive traffic to their websites which functioned as landing pages $(20 \%)$. Some of them outsource their financial and marketing activities to third parties $(20 \%)$. Most of the respondents who trusted the most as their suppliers in this study were the MOKA application. Moka is an associate company of Gojek that provides various solutions for offline $\&$ online sales needs. Moka has a very sophisticated POS system that can help offline sales and allows MSMEs to build personal websites through GoStore. Moka POS is a cloud-based Point of Sale system that can help offline sales activities. This application provides services with complete features, namely daily transaction reports, promotional activities, storage \& inventory management, as well as access to dashboards and real-time reports. And what's interesting is that some have tried to implement a business auto pilot scheme in their business (10\%). Moka has a very sophisticated POS system that can help offline sales and allows MSMEs to build personal websites through GoStore. Moka POS is a cloud-based Point of Sale system that can help offline sales activities. This application provides services with complete features, namely daily transaction reports, promotional activities, storage \& inventory management, as well as access to dashboards and real-time reports. And what's interesting 
is that some have tried to implement a business auto pilot scheme in their business (10\%). Moka has a very sophisticated POS system that can help offline sales and allows MSMEs to build personal websites through GoStore. Moka POS is a cloud-based Point of Sale system that can help offline sales activities. This application provides services with complete features, namely daily transaction reports, promotional activities, storage \& inventory management, as well as access to dashboards and real-time reports. And what's interesting is that some have tried to implement a business auto pilot scheme in their business $(10 \%)$. as well as access to real-time dashboards and reports. And what's interesting is that some have tried to implement a business auto pilot scheme in their business $(10 \%)$. as well as access to real-time dashboards and reports. And what's interesting is that some have tried to implement a business auto pilot scheme in their business $(10 \%)$.

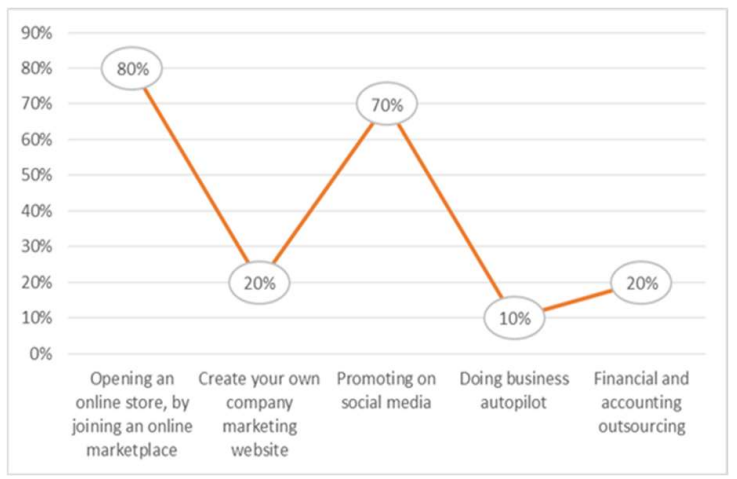

Fig. 6. Digital Business Strategies.

The Auto-Pilot business is a condition where the business can run on its own without the owner always being actively involved in it. That is, the business can run alone, the business owner can go for a walk. This means that apart from financial freedom, the business owner also has time freedom. Of course, this takes advantage of various available applications to help business owners continue to monitor their companies even remotely.

The last question asked is what exactly you are doing so that the effectiveness of your digital marketing efforts can be run well, and the traffic that comes to your landing page will increase significantly. Then the answer is automate my email marketing (7\%), use website builder (5\%), Integrated my application (5\%), use a scheduling tool for social media (5\%), Run Automated Survey Responses (5\%) and none of the above $(70 \%)$.

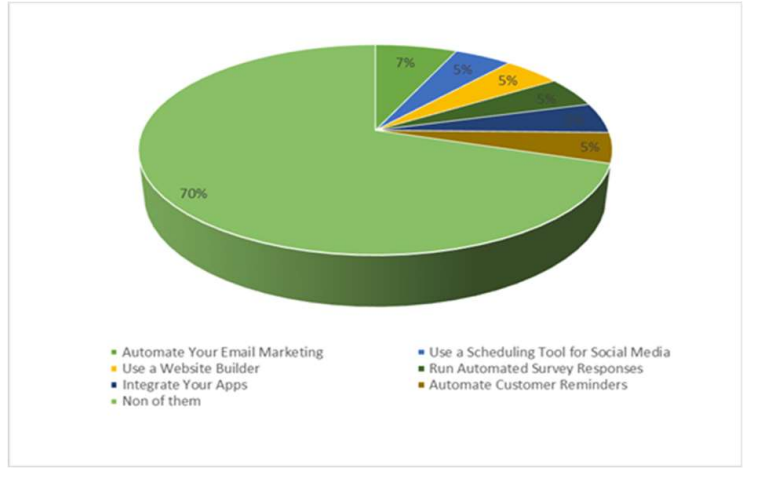

Fig. 7. Intention to have auto-pilot business.

This means that even though they have used digital platforms to maximize their revenue, not many have used strategies to maximize the traffic that comes to their stores. Plus, their penetration into online businesses is also that the majority of them only join the e-market place. Whereas optimal results will be obtained if they can sell themselves through their own website using various existing and available strategies to maximize their sales. Thus, he does not need to share profits with e-marketplaces which can make his ability to maintain the level of liquidity and solvency of the company to be lower to keep the company operating.

\section{Conclusion}

From the results of the research conducted, it appears that SMEs in Aceh actually have a comparative advantage because they can utilize raw materials obtained from Aceh's nature without having to bring in from outside. Its comparative advantage can be converted into a competitive advantage because it can sell at a lower price. In the era of the pandemic, the average MSME in Aceh experienced financial difficulties, so they hoped that financial assistance from the government through existing credit channelling banks would make it easier for them to get out of the financial crisis caused by the COVID-19 pandemic. The assistance in question can be in the form of grants or ease of requirements in lending business loans. The Singapore government has also done the same for its MSMEs. In addition to providing grants for the digitization of its MSME companies, the Singapore Government also helps MSMEs with credit risk from financial institutions of up to 90 percent. This proves the government's seriousness is the same as in Indonesia to help their SMEs survive this pandemic.

In addition to hoping for a helping hand from the government, MSME business actors in Aceh have also made various efforts that they consider to be able to ensure the survival of their businesses during this pandemic, for example by increasing cost efficiency, including by reducing temporary employees, reducing the amount of production, Application for working capital, credit with lighter terms, looking for new funding sources in the form of grants and migrate to business digital without leaving the existing offline business. 


\section{References}

1. A. Dua, K. Ellingrud, D. Mahajan D, J. Silberg McKinsey Co. (2020)

2. N.F. Fabeil, K.H. Pazim, J. Langgat. T. J Econ Bus. 3, 2. (2020)

3. K.F. Sandy. Survei BI (2021)

4. R. Fairlie. National Bureau of Economic Research (2020)

5. L. Demmou, OECD Working Papers. (2021).

6. OECD. OECD Policy Responses to COVID-19. (2021).

7. OECD. OECD SME and Entrepreneurship Papers. (2020)

8. E. Kiran, Gaziantep Univ J Soc Sci 752-66. (2020)

9. D. Graeber, A.S. Kritikos, J. Seebauer. J Popul Econ. 34(4), 1141-87 (2021).
10. J.Z. Ayanian. JAMA Heal Forum 1(6), e200689. (2020)

11. R. Zhang, Cold Spring Harbour Laboratory (2021).

12. M. Albert. Australia's Economic Measures and Employment Laws Changes in Response to Covid19 (2020).

13. S. Kalemli-Ozcan, P-O. Gourinchas, V. Penciakova, N. Sander. IMF Work Pap 20, 207. (2020)

14. M. Brülhart, R. Lalive, T. Lehmann, M. Siegenthaler, Swiss J Econ Stat 156, 1 (2020)

15. F. Eckert, H. Mikosch, Swiss J Econ Stat (2020).

16. S. Kalogiannidis. Int J Soc Sci Econ Invent. 6(12), 387-to. (2020)

17. S. Lund, A. Madgavkar, J. Manyika, S. Smit, K. Ellingrud. McKinsey (2020).

18. M. Syahran. Ekonomi dan Bisnis (2021)

19. R.D. Fred. Manajemen Strategi dan Konsep. 12th ed. Jakarta: Salemba Empat; (2011).

20. W. Fathiyah, Voice of Indonesia. (2021)

21. S. Hollander, A. Verriest. J finance Econ (2016) 